\title{
Natural frequencies and damping ratios of Norway spruce (Picea abies (L.) Karst) growing on subalpine forested slopes
}

\author{
M. J. Jonsson · A. Foetzki $\cdot$ M. Kalberer • \\ T. Lundström $\cdot$ W. Ammann $\cdot$ V. Stöckli
}

Received: 20 January 2006/Revised: 13 May 2007/ Accepted: 15 May 2007/Published online: 24 July 2007

(C) Springer-Verlag 2007

\begin{abstract}
We investigated the natural frequencies and damping ratios of 24 Norway spruce trees (Picea abies (L.) Karst) growing on subalpine forested slopes using swaying experiments. Trees were winched to the release position using a manually operated cable winch. Before release, the stem base rotation was approximately 2 degrees. All trees were tested in both fall-line and cross-slope direction if possible to reveal the difference between the two perpendicular directions. A new method based upon the Hilbert transformation for evaluating the damping ratio for trees was used. It enabled us to investigate the damping ratio for all excited modes of vibration in the tree structure during the swaying experiments and to study if velocity proportional damping (viscous damping) is a reasonable assumption when predicting the tree response to different external actions using mechanical models. No difference in first natural frequency and damping ratio was found between the fall-line and cross-slope direction for all tested trees. The first natural frequencies correlated best with the diameter at breast height and squared total tree height $D B H / H^{2}$. For the damping ratio, no significant correlation with different tree characteristics could be found. A nonvelocity proportional damping ratio was observed for two trees. This indicates that using a viscous damping for all
\end{abstract}

Communicated by T. Speck.

M. J. Jonsson ( $\square)$

BergByggKonsult AB, 17134 Solna, Sweden

e-mail: martin.jonsson@bergbyggkonsult.se

A. Foetzki - M. Kalberer · T. Lundström ·

W. Ammann · V. Stöckli

WSL Swiss Federal Institute for Snow and Avalanche Research

SLF, 7260 Davos, Switzerland frequencies is an appropriate simplification when modelling the wind-tree interaction.

Keywords Hilbert transformation · Swaying experiments · Tree mechanics $\cdot$ Tree stability $\cdot$ Tree-wind interaction

\section{Introduction}

The natural frequencies and the damping characteristics of a tree are important parameters when modelling the wind-tree interaction. A tree absorbs wind energy at all its natural frequencies, however, most energy is absorbed at the tree's first natural frequency (Holbo et al. 1980; Mayer 1989; Peltola 1996). The relationship between the natural frequencies of the tree and the frequency of the acting wind provides guidelines on how to model the wind induced swaying of a tree (Wood 1996). A wide range of trees has been tested for their first natural frequencies (Gardiner 1989; Roodbaraky et al. 1994; Moore and Maguire 2004). Milne (1991) investigated Sitka spruce (Picea sitchensis (Bong.) Carr) trees growing on flat ground in Scottish plantation in two perpendicular directions without finding any difference in the natural frequencies. Baker (1997) tested urban lime trees (Tilia $\times$ europea) during both summer and winter conditions and found that the measured frequencies were larger in winter compared to the summer.

The damping of trees is grouped into internal and external damping (Hoag et al. 1971). Internal damping is due to energy dissipation in the root-soil system and internal friction within the wood material of the stem and the branch system (Milne 1991; Wood 1996; Moore and Maguire 2004). External damping is due to aerodynamic drag of the crown and due to collision with neighbouring 
trees (Milne 1991). When studying the contribution from each of these terms to the total damping, the ratio between damping due to contact with neighbouring trees, aerodynamic damping, and damping in the tree stem and root system is found to be $\sim 50 / 40 / 10 \%$, respectively (Milne 1991). However, this relationship might not be constant because the damping ratio is often non-linear and amplitude dependent (Moore and Maguire 2004). Furthermore, the aerodynamic damping also increases with wind speed (Wood 1996).

A damping model can describe energy dissipation in a dynamic system. For a natural system like a tree, this model is complex and difficult to define, as the dissipation mechanisms are not completely understood. It is therefore common to assume that the damping is proportional to the velocity, so-called viscous-damping. With this assumption, the damping coefficient can be determined with experimental methods like the logarithmic decrement, the resonant amplification method, and the half-power (bandwidth) method (Clough and Penzien 1993). The simplest and most common method to evaluate the damping is the logarithmic decrement. With this method, the damping is evaluated in the time-domain and calculated between two adjacent amplitude peaks, or averaged over several peaks in the measured signal. With the resonant amplification method and the half-power method, the damping is evaluated in the frequency-domain. Plotting the measured displacement against the frequency, a frequency-response curve is obtained. Outgoing from the peak in the frequency-response curve, the damping ratio can be estimated using the resonant amplification method. Instead of using the peak in the frequency-response curve, the half-power method uses the maximum value divided with the factor $\sqrt{2}$. For more information about the different methods, see Clough and Penzien (1993).

None of the above mentioned methods are sufficient to obtain the continuous relationship between the damping and the amplitude of the oscillation. However, using the resonant amplification method and the half-power method, the damping ratio can be calculated for all excited modes (Clough and Penzien 1993). Using the Hilbert transformation, the continuous relationship between damping ratio and oscillation amplitude can be calculated as the damping ratio is evaluated between two adjacent points in the measured signal and not between the amplitude peaks (Agneni and Balis-Crema 1989; Johnson 1999). Furthermore, a signal recorded from a free vibration experiment (acceleration, velocity or displacement) contains in most cases the contribution of many different vibration modes excited by the applied initial deformations (Agneni and Balis-Crema 1989). By separating the measured signal into all excited modes using a frequency filter, the damping ratio for every mode can be investigated.
Norway spruce (Picea abies (L). Karst) trees were selected in this study because is it the most common species in European subalpine forests (Ellenberg 1996). These trees are often found in protection forests and have a defence capacity against natural hazards such as rockfalls and avalanches (Bartelt and Stöckli 2001; Dorren and Berger 2006). The swaying experiment presented in this paper is the first experiment in a series of three, with the aim to finally investigate the complex interaction between a rock and a tree. The swaying experiments were followed by winching experiments to $\sim 2.5^{\circ}$ rotation at stem base (Jonsson et al. 2006), and finally full-scale rockfall experiments (Lundström et al. 2007b). A method based upon the Hilbert transformation was applied to 24 Norway spruce trees subjected to swaying experiments in the fallline and the cross-slope direction in order to investigate both the damping ratio and whether the damping ratio is proportional to the velocity, the so called viscous-damping.

\section{Materials and methods}

Experimental sites and overview of the swaying experiments

Three different experimental sites were used to perform the swaying experiments in subalpine forests near Davos, Switzerland, during the vegetation periods of 2003 and 2004 (Table 1). The soil at all experimental sites is podzolic brown earth (well graded gravel with silt and sand) with a high proportion of stones. The surroundings of Davos is characterised by an alpine topography with peaks reaching $3100 \mathrm{~m}$. The dominant wind direction in the valley is north to south with the strongest winds coming from north (Meteoschweiz 2004). The magnitude of the strongest wind is approximately $20 \mathrm{~m} / \mathrm{s}$ and the average wind calculated for every 30-min period is approximately $2 \mathrm{~m} / \mathrm{s}$. Both values evaluated between 1998 and 2006 (Unpublished data SLF).

Davos has a mean annual precipitation of $1,082 \mathrm{~mm}$ (January $74 \mathrm{~mm}$, August $146 \mathrm{~mm}$ ) and an annual mean temperature of $2.8^{\circ} \mathrm{C}$ (January $-5.3^{\circ} \mathrm{C}$, August $10.8^{\circ} \mathrm{C}$ ) evaluated between 1961 and 1990 (Meteoschweiz 2004).

Table 1 Average slope angle, location, and exposition of the test sites

\begin{tabular}{lllll}
\hline Test site & $\begin{array}{l}\text { Slope } \\
\text { angle }\end{array}$ & Latitude & Longitude & Exposition \\
\hline Mattawald (1) & $34^{\circ}$ & $9^{\circ} 50^{\prime} 24^{\prime \prime}$ & $46^{\circ} 47^{\prime} 42^{\prime \prime}$ & NW \\
Brüchwald (2) & $32^{\circ}$ & $9^{\circ} 48^{\prime} 12^{\prime \prime}$ & $46^{\circ} 46^{\prime} 59^{\prime \prime}$ & SO \\
Seehornwald (3) & $10^{\circ}$ & $9^{\circ} 51^{\prime} 7^{\prime \prime}$ & $46^{\circ} 48^{\prime} 55^{\prime \prime}$ & SW \\
\hline
\end{tabular}


The trees on the three test sites were all mature trees with a mean diameter at breast height $\mathrm{DBH}$ ( \pm one standard error) $0.32 \pm 0.14,0.40 \pm 0.15$, and $0.26 \pm 0.10 \mathrm{~m}$, and dominant height of $33.0,35.0$, and $28.0 \mathrm{~m}$, respectively. The stand density for respective test site was 450, 320, and 580 trees per hectare.

Twenty-four Norway spruce trees (P. abies (L.) Karst) growing on slopes in subalpine forests were tested in swaying experiments. The tested trees were selected so that the full-scale rockfall tests could be performed (Lundström et al. 2007b), this implied that some trees could not be tested by means of swaying experiments in both fall-line and cross-slope direction because of crown interaction with other trees. After the trees had fallen to the ground, either by the simulated rock or manually winched, tree characteristics, such as stem-diameter and stem-weight from the base to the tree top $H$, starting point of tree crown, length of the branches, and weight of the tree crown per meter were measured.

To get the tree into position before the swaying experiments, a steel cable was mounted at $75 \%$ of total tree height $H$ (Fig. 1), which is approximately 15.6$25.9 \mathrm{~m} \pm 0.1 \mathrm{~m}$, depending upon tree height (Table 2). In order to mount these sensors on the tree stem, it was necessary to climb the tree (Fig. 1). When climbing the tree stem, only a minimum of branches was removed in order to maintain the tree crown as intact as possible and thus to minimize the influence on the natural frequencies and the damping ratios.

All trees were winched to the release position using a manually operated cable winch. The trees were pulled until $\sim 2^{\circ}$ stem base rotation. This corresponds to a horizontal deflection of the winching point of approximately $2 \mathrm{~m}$. Two sensors mounted at 53 and $75 \%$ of $H$ in the swaying direction (Fig. 1) recorded the acceleration after release.
The sensors used for the swaying tests were of the type AMOS-ABM-25 (AMOS Sensoren \& Meßtechnik, Ludwigshafen, Germany) featuring a range of $10 \mathrm{~m} / \mathrm{s}^{2}$ and a precision of $0.2 \mathrm{~m} / \mathrm{s}^{2}$. The sampling rate for both sensors was $20 \mathrm{~Hz}$.

Approach used for analysis of natural frequencies and damping ratios

A method to obtain the continuous relationship between the damping and the amplitude of the oscillation based upon the properties of the Hilbert transformation is proposed in Agneni and Balis-Crema (1989). An overview of this method is given below. The equation of motion for a linear single degree of freedom system can be written

$m \ddot{x}(t)+c \dot{x}(t)+k x(t)=P(t)$

where $x(t)$ is the displacement and $\ddot{x}(t)$ and $\dot{x}(t)$ are the acceleration and velocity, respectively. The parameters $m, c$, and $k$ describe the mass, damping, and the stiffness for the system. For free vibrations, no forces are present, i.e. the acting force $P(t)$ is zero (Bachmann and Ammann 1987). Assuming viscous damping, $c$ can be expressed as

$c=2 m \xi \omega$

where $\xi$ is the damping ratio (the proportion of critical damping) and $\omega$ the angular frequency of the system expressed as

$\omega=2 \pi f$

The analytical solution to the equation of motion can then be expressed as
Fig. 1 a The real test-set up for the test in fall-line direction and the positions of the two sensors and the original stem configuration. In the lower right corner, the sensor used as well as how they were attached to the tree stem can be seen. b The schematic test set-up for the fall-line direction, $0.53 \mathrm{H}$ and $0.75 \mathrm{H}$ indicate the positions of the sensors, the pulling height was $0.75 H, H$ total tree height, $\beta_{\mathrm{s}}$ slope angle, $\delta_{\mathrm{h}}$ horizontal deflection of the winching point before release, $\Phi$ stem base rotation

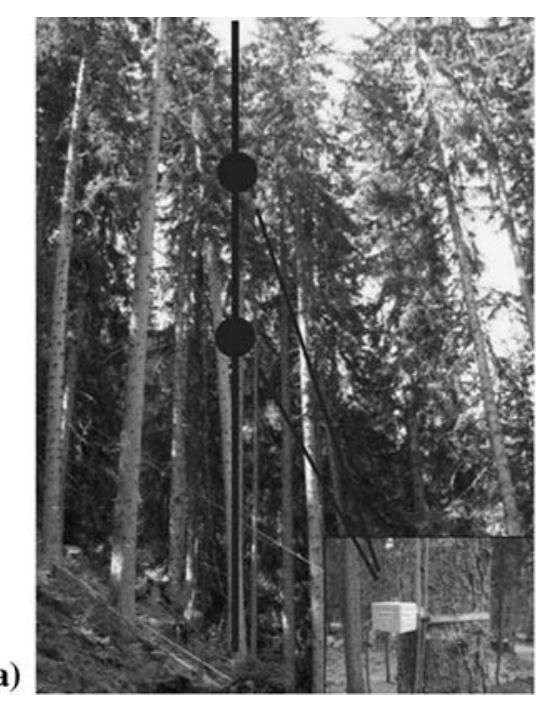

b)

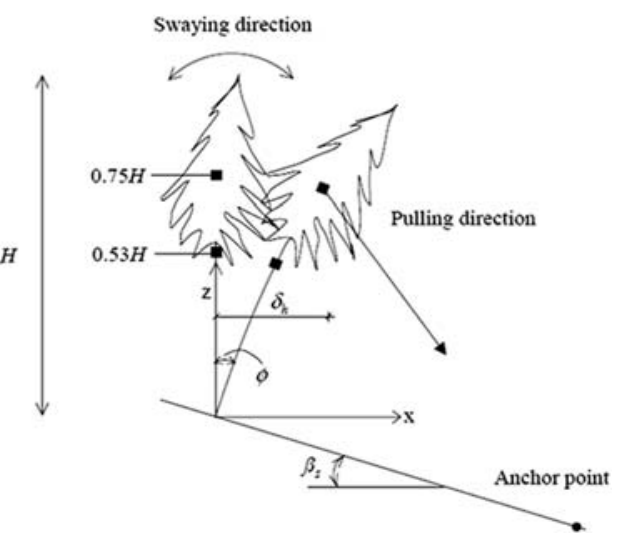


Table 2 Calculated first natural frequency $f_{1}$, and corresponding damping ratio of the test trees for all three test sites in both fall-line and in cross-lope directions $\xi_{1 / 0.53 H}$ and $\xi_{1 / 0.75 H}$ are the damping ratios calculated for the sensors at 53 and $75 \%$ of the total tree height, respectively. An empty cell indicates that the tree was not tested in this direction, or that no value was obtained during the evaluation of the test results $H$, total tree height
$D B H$, Diameter at breast height;

\begin{tabular}{|c|c|c|c|c|c|c|c|c|c|}
\hline \multirow[t]{2}{*}{ Test- site } & \multirow[t]{2}{*}{ Tree no. } & \multirow[t]{2}{*}{$D B H(\mathrm{~m})$} & \multirow[t]{2}{*}{$H(\mathrm{~m})$} & \multicolumn{3}{|l|}{ Fall-line } & \multicolumn{3}{|c|}{ Cross-slope } \\
\hline & & & & $f_{1}(\mathrm{~Hz})$ & $\begin{array}{l}\xi_{1 / 0.53 H} \\
(\%)\end{array}$ & $\begin{array}{l}\xi_{1 / 0.75 H} \\
(\%)\end{array}$ & $f_{1}(\mathrm{~Hz})$ & $\begin{array}{l}\xi_{1 / 0.53 H} \\
(\%)\end{array}$ & $\begin{array}{l}\xi_{1 / 0.75 H} \\
(\%)\end{array}$ \\
\hline \multirow[t]{7}{*}{1} & 1 & 0.40 & 31.3 & 0.20 & 8.62 & 8.46 & & & \\
\hline & 2 & 0.39 & 34.1 & 0.14 & 4.95 & 5.03 & 0.16 & 4.43 & 4.37 \\
\hline & 3 & 0.49 & 33.3 & 0.20 & 4.07 & 4.02 & 0.22 & 4.11 & 3.98 \\
\hline & 5 & 0.44 & 30.0 & 0.18 & 6.82 & 6.75 & 0.22 & 5.59 & 5.59 \\
\hline & 7 & 0.43 & 30.0 & 0.22 & 5.29 & 5.37 & & & \\
\hline & 11 & 0.27 & 21.0 & 0.25 & 2.89 & 2.98 & 0.22 & 4.22 & 4.14 \\
\hline & 12 & 0.23 & 21.3 & 0.25 & 4.50 & 4.69 & 0.27 & 4.30 & 4.57 \\
\hline \multirow[t]{10}{*}{2} & 1 & 0.35 & 25.6 & 0.22 & 6.06 & 5.79 & 0.21 & 7.65 & 7.50 \\
\hline & 2 & 0.48 & 32.9 & 0.17 & 5.96 & 5.85 & 0.20 & 5.04 & 4.88 \\
\hline & 3 & 0.44 & 29.9 & 0.20 & 6.92 & 6.77 & 0.22 & 4.32 & 4.25 \\
\hline & 4 & 0.58 & 33.5 & 0.23 & 3.78 & 3.87 & & & \\
\hline & 5 & 0.43 & 27.9 & 0.21 & & & 0.22 & 6.75 & 6.50 \\
\hline & 6 & 0.22 & 20.7 & 0.29 & 6.94 & 6.86 & 0.29 & 9.41 & 8.82 \\
\hline & 7 & 0.38 & 24.6 & 0.26 & 6.03 & 5.88 & 0.27 & 4.73 & 4.48 \\
\hline & 8 & 0.35 & 25.4 & 0.27 & 5.18 & 5.71 & 0.30 & 5.21 & 5.28 \\
\hline & 9 & 0.50 & 34.5 & 0.22 & 4.00 & 4.20 & 0.22 & 3.76 & 3.69 \\
\hline & 10 & 0.51 & 32.0 & 0.25 & 3.80 & 3.79 & 0.25 & 3.66 & 3.56 \\
\hline \multirow[t]{7}{*}{3} & 1 & 0.32 & 26.7 & 0.27 & 4.78 & 4.37 & & & \\
\hline & 4 & 0.37 & 27.0 & 0.24 & & & 0.24 & & \\
\hline & 5 & 0.29 & 27.0 & 0.18 & 4.42 & 4.33 & 0.19 & 3.44 & 3.44 \\
\hline & 6 & 0.39 & 26.9 & 0.25 & 3.85 & 3.90 & 0.23 & 3.83 & 3.60 \\
\hline & 7 & 0.33 & 24.5 & 0.19 & 4.47 & 4.45 & 0.19 & 4.30 & 4.26 \\
\hline & 8 & 0.36 & 27.7 & & & & 0.26 & 5.04 & \\
\hline & 9 & 0.42 & 28.1 & 0.28 & 3.01 & 2.97 & & & \\
\hline
\end{tabular}

$f\left(t_{k}\right)=\frac{a_{0}}{2}+\sum_{n=1}^{N / 2}\left(a_{n} \cos \left(\frac{2 \pi n k}{N}\right)+b_{n} \sin \left(\frac{2 \pi n k}{N}\right)\right)$.

A tree is a complex mechanical system with many degrees of freedoms. For such a system, the final motion can be approximated as a sum of all excited modes (Agneni and Balis-Crema 1989). This implies that for a measured acceleration $a(t)$, from a swaying experiment, that contains $M$ excited modes and assumed viscous damping, the acceleration can be expressed as

$a(t)=\sum_{n=1}^{M} A^{n} \mathrm{e}^{-\xi^{n} \omega_{\mathrm{d}}^{n} t} \sin \left(\omega_{\mathrm{d}}^{n} t+\psi^{n}\right)$.

where $A^{n}$ is the amplitude, $\psi^{n}$ the phase shift, $\xi^{n}$ the damping ratio (i.e. the ratio between the actual and the critical damping), and $\omega^{n}{ }_{\mathrm{d}}$ the damped angular frequency for mode $n$. Every periodic signal can be written as a series of sine and cosine terms (Clough and Penzien 1993). When the series is defined only by a number of finite points $N$, the measured signal can be represented by the finite series, at $t=t_{k}, k=1, \ldots, N$ the measured signal can be written as
The result of the Hilbert transformation is the original signal plus a complex part (the original signal phase shifted $90^{\circ}$ ). Rewriting Eq. (6) with the assumption that the acceleration is zero at the beginning of the test, and that the tree is oscillating around the $z$ axis (Fig. 1), the following expression is obtained

$$
\begin{aligned}
h\left(t_{k}\right)= & \sum_{n=1}^{N / 2}\left[\left(a_{n} \cos \left(\frac{2 \pi n k}{N}\right)+b_{n} \sin \left(\frac{2 \pi n k}{N}\right)\right)\right. \\
& \left.+i\left(a_{n} \cos \left(\frac{2 \pi n k}{N}+\frac{\pi}{2}\right)+b_{n} \sin \left(\frac{2 \pi n k}{N}+\frac{\pi}{2}\right)\right)\right] .
\end{aligned}
$$

Making use of basic trigonometric relationships, Eq. (7) can for a specific time step be written as 
Fig. 2 a The recorded acceleration plotted in the time domain. b The recorded acceleration transferred to the frequency domain using the Fourier transformation shows the calculated power spectra and the two excited frequencies. c The envelope was fitted using the least square method in a $\log$ plot. The slope of the fitted line divided by the angular frequency $\omega_{\mathrm{d}}^{n}$, was defined as the damping ratio $\xi^{n}$
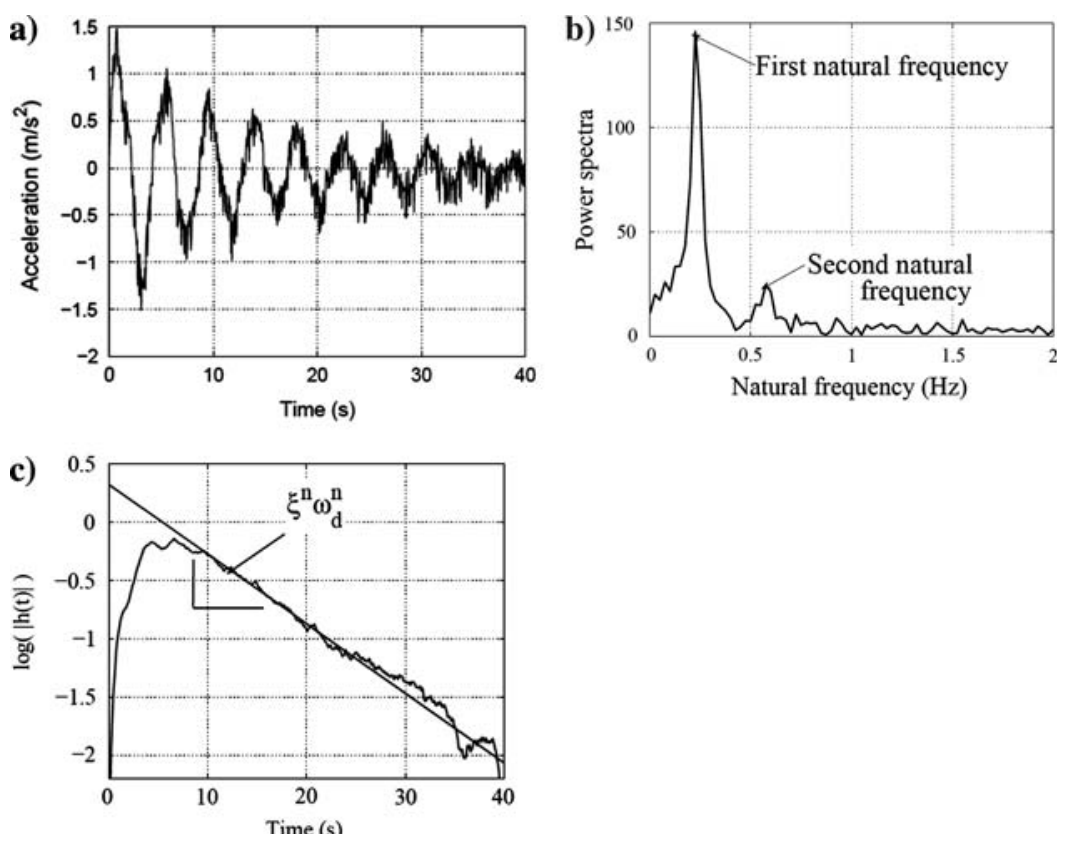

$$
\begin{aligned}
h\left(t_{k}\right)= & \sum_{n=1}^{\frac{N}{2}}\left[\left(a_{n} \cos \left(\frac{2 \pi n k}{N}\right)+b_{n} \sin \left(\frac{2 \pi n k}{N}\right)\right)\right. \\
& \left.+i\left(-a_{n} \sin \left(\frac{2 \pi n k}{N}\right)+b_{n} \cos \left(\frac{2 \pi n k}{N}\right)\right)\right] .
\end{aligned}
$$

Calculating the amplitude of the signal given by Eq. (8) for every time step, the following expression is obtained

$$
\left|h\left(t_{k}\right)\right|=\sqrt{a_{n}^{2}+b_{n}^{2}}
$$

Thus, performing this operation for all time steps, the envelope of the signal is obtained. To investigate the properties of only one frequency at a time, the measured signal is filtered to obtain the frequency of interest. Every frequency found in the signal can then be expressed as

$a(t)=A^{n} \mathrm{e}^{-\xi^{n} \omega_{\mathrm{d}}^{n} t} \sin \left(\omega_{\mathrm{d}}^{n} t+\psi^{n}\right)$.

Calculating the envelope for every frequency that was found during the analysis and plotting the relationship in a logarithm plot, the slope of the curve will be the variation in time of $\xi^{n} \omega^{n}$. If the damping is linear, a first order polynomial will be sufficient to fit this curve (Johnson 1999). In this study, the envelope was fitted using a regression analysis with a first order polynomial. Note that if the envelope cannot be approximated using a first order polynomial, the damping is non-linear. This can mean that the damping is either dependent on the amplitude of the oscillation or not viscous at all. The main steps needed to obtain an estimation of the damping ratios $\xi^{n}$ and the natural frequencies $f_{n}$ through Hilbert transformation can be summarized as follows.

- The recorded acceleration was plotted in the time domain and the interesting part (IP) of the acceleration was selected for future analysis. The minimum requirement for IP was set to six swaying cycles but eight or more cycles were used in most cases (Fig. 2a).

- IP is transferred to the frequency domain using the Fourier transformation with the obtained power spectra showing all the frequencies $f_{n}$ excited during the test (Fig. 2b).

- IP was filtered, using a first order Butterworth filter.

- Thereafter, the Hilbert transformation was used to obtain the envelope of IP as a function of time (Fig. 2c).

- Finally, the slope of the fitted line divided by $\omega^{n}{ }_{\mathrm{d}}$ is defined as the damping ratio $\xi^{n}$ (Fig. 2c).

After estimating the first natural frequency $f_{n}$ of every tree using the procedure outlined in the previous paragraphs, a statistical investigation using the commercial software Splus $^{\circledR}$ (Insightful Corporation, Seattle, Washington, USA) was carried out. Aim of the statistical investigation was to find the most meaningful correlation between $f_{n}$ and other important mechanical and geometrical characteristics of the tree. A physical meaningful regression line with tree characteristics such as diameter at breast height $D B H$, total tree height $H$, crown base, and crown length, etc. was always searched, i.e., the intersection was forced to go through zero. For the regression analysis, the sum of squared errors $R^{2}$ was calculated, and the significance of the polynomial 
Table 3 Calculated second natural frequency $f_{2}$, and corresponding damping ratio in fall-line and cross-slope directions

\begin{tabular}{|c|c|c|c|c|c|c|c|}
\hline \multirow{2}{*}{$\begin{array}{l}\text { Test } \\
\text { site }\end{array}$} & \multirow{2}{*}{$\begin{array}{l}\text { Tree } \\
\text { no. }\end{array}$} & \multicolumn{3}{|c|}{ Fall-line } & \multicolumn{3}{|c|}{ Cross-slope } \\
\hline & & $\begin{array}{l}f_{2} \\
(\mathrm{~Hz})\end{array}$ & $\begin{array}{l}\xi_{2 / 0.53 H} \\
(\%)\end{array}$ & $\begin{array}{l}\xi_{2 / 0.75 H} \\
(\%)\end{array}$ & $\begin{array}{l}f_{2} \\
(\mathrm{~Hz})\end{array}$ & $\begin{array}{l}\xi_{2 / 0.53 H} \\
(\%)\end{array}$ & $\begin{array}{l}\xi_{2 / 0.75 H} \\
(\%)\end{array}$ \\
\hline \multirow[t]{2}{*}{1} & 2 & 0.43 & 3.27 & 3.78 & 0.46 & 4.50 & 4.95 \\
\hline & 7 & 0.72 & & 2.74 & & & \\
\hline \multirow[t]{2}{*}{2} & 4 & 0.56 & 3.18 & 3.72 & & & \\
\hline & 8 & 0.79 & 5.27 & 4.50 & 0.77 & 4.58 & 5.53 \\
\hline
\end{tabular}

$\xi_{2 / 0.53 H}$ and $\xi_{2 / 0.75 H}$ are the damping ratios calculated for the sensors at 53 and $75 \%$ of the total tree height, respectively. An empty cell indicates that the tree was not tested in this direction, or that no value was obtained during the evaluation of the test results

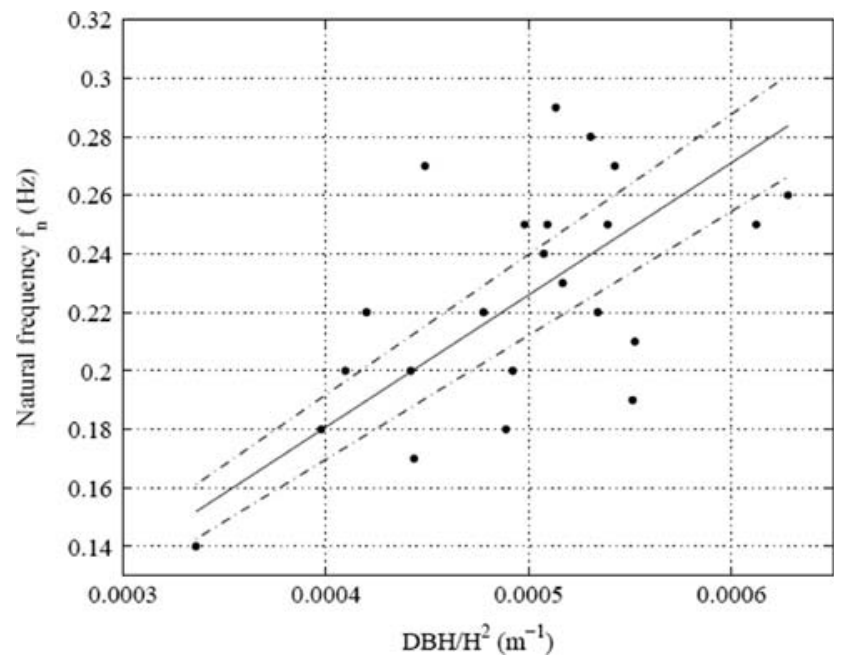

Fig. 3 First natural frequency $f_{n}$ for the 23 tests in fall-line direction. The straight line indicates the best regression line, $p_{1} \times D B H / H^{2}$, $p_{1}=454.53$ and $R^{2}=0.31$

coefficients was controlled using the $F$ test. All experiments in fall-line direction were evaluated together. To investigate the difference between first natural frequency and damping in the fall-line and the cross-slope direction, and in the damping between 53 and $75 \%$ of $H$, the Wilcoxon test for paired differences was used.

\section{Results}

For all the tested trees, both the natural frequencies and the damping ratio were calculated for every mode excited during the swaying experiment (Tables 2, 3). No differences could be found between natural frequencies in fall-line and cross-slope direction for trees growing at experimental site 2 . For this reason, it was assumed that the natural frequencies in fall-line direction could be used to represent the natural frequencies for the tree structure.

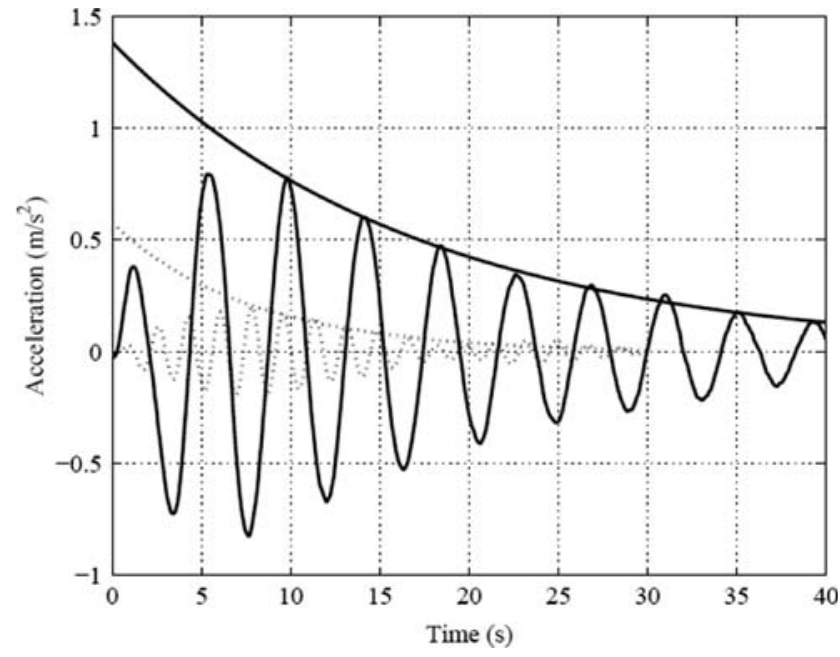

Fig. 4 Measured acceleration from sensor at $75 \%$ of $H$ for test in fallline direction, tree 4, experimental site 2, separated into its two excited frequencies. The solid line represents the first natural frequency $f_{1}=0.23 \mathrm{~Hz}$, damping ratio $\xi_{1 / 0.75 H}=3.18 \%$, the dashed line the second natural frequency $f_{2}=0.56 \mathrm{~Hz}$, damping ratio $\xi_{2 / 0.75 H}=3.78 \%$

The first natural frequency was best explained by the relationship $p_{1} \times D B H / H^{2}, p_{1}=454.53, P<0.001$ with a $R^{2}=0.31$ (Fig. 3). No significant correlation was found between damping ratio and tree characteristics such as $D B H, H$, crown base, and crown length, etc.

For four trees, more than one frequency was excited and observed (Table 3). The amplitudes of the two separated oscillations were different, with the amplitude for the second oscillation always smaller (Fig. 4).

The statistical analysis showed that the damping ratio at $75 \%$ of $H$ was slightly higher than at $53 \%$ of $H$. No statistical difference in damping ratio was found between fall-line and cross-slope direction. A non-linear damping was observed for two trees. For these trees, the damping ratio was not calculated. However, the low amount of observed trees showing a non-linear damping ratio indicate that using a velocity proportional damping (viscous damping) when modelling tree structural damping is a appropriate assumption. Comparing the damping ratio between the first and the second mode of vibration $(n=3)$ in fall-line direction using data from the sensor mounted at $0.53 \mathrm{H}$ showed that the damping ratio were of the same order of magnitude.

\section{Discussion}

Damping

Using the properties of the Hilbert transformation (Agneni and Balis-Crema 1989; Johnson 1999) to evaluate the 
damping ratio showed results in accordance with known literature values, which are approximately 4-15\% (Moore and Maguire 2004). However, the values presented in this paper are closer to the lower part of this range. The internal damping ratio is generally lower than 5\% (Moore and Maguire 2004), thus this might indicate that the contribution from the external damping for our trees, represents a minor part of the total damping ratio. This seems logical because all the trees were selected to minimize the interaction with neighbouring trees.

A common simplification when evaluating the damping is to assume viscous damping, which is proportional to the velocity (Clough and Penzien 1993; Moore and Maguire 2004). However, the damping is in most cases dependent upon the amplitude of the oscillation (Clough and Penzien 1993; Moore and Maguire 2004). The structural damping is a combination of internal and external damping (Moore and Maguire 2004). Wood (1996) mentioned that the external damping is not constant, and that the aerodynamic damping increases with wind speed. The reason for this increase is because the stiffness and damping coefficients are displacement dependent in reality (Gardiner 1992). For all 24 trees evaluated in this investigation, a non-velocity proportional damping ratio is only observed twice. The reason for this finding could be that these trees interacted with neighbouring trees, even though we tried to minimize this influence. The damping ratio for the second mode of vibration is evaluated for four trees and the results show that the damping ratios for both the first and second mode of vibration are of the same order of magnitude (Tables 2, 3). These results indicate that using a viscous damping for all modes of vibration is an appropriate simplification when modelling the wind-tree interaction. The constant damping ratio might be due to the small amplitude in our swaying experiments and that no interaction with neighbouring trees occurred. Winching the tree to a stem base rotation of $\sim 2^{\circ}$, a horizontal deflection of the winching point $(0.75 H)$ of approximately $1-2 \mathrm{~m}$ is obtained (Fig. 1). We therefore suggest future swaying experiments with larger vibration amplitudes to be performed.

No significant correlation could be found between tree structural parameters such as $D B H$ and tree height and the damping ratio for the tree. The same has been observed in White et al. (1976) as well as in Moore and Maguire (2004). Furthermore, Milne (1991) investigated the difference in damping ratio in two perpendicular directions of Picea sitchensis (Bong.) Carr trees. He found a difference originating from asymmetric crown shape and contact with neighbouring trees. Our results could not verify his findings, as the crown shapes of the trees in our investigation were quite symmetric.
Natural frequency

No difference was found in first natural frequencies between fall-line and cross-slope direction. This is in accordance with earlier observations of Milne (1991), who investigated the first natural frequencies in two perpendicular directions of Sitka spruce (Picea sitchensis (Bong)) trees growing on flat ground in a Scottish plantation. Although the root architecture is asymmetric on slopes (Di Iorio et al. 2005, and own unpublished data), the first natural frequencies do not differ in the respective directions. This indicates that root architecture does not have a major influence on the first natural frequency. However, to what extent the form and size of the root-soil plate influences the frequencies cannot be revealed with the data available. Its influence must be further investigated to determine its importance.

The first natural frequency for trees growing in subalpine terrain is best related to squared total tree height $H$ and diameter at breast height $D B H$ (Fig. 3). This relationship is also suggested by Moore and Maguire (2004). The differences between the three experimental sites for both the natural frequencies and the damping ratio were not statistically analysed, as the variance within the experimental sites were larger than for all experimental sites combined. During these tests, a weak correlation $R^{2}=0.31$ was found. There might be several explanations for this. The investigated regression model is theoretically derived in Gardiner (1992). This relationship assumes the ratio between the wood density and Young's modulus of elasticity to be approximately constant over the tree height. However, investigations on Norway spruce trees have shown that density increases and that Young's modulus of elasticity decreases with increasing tree height (Lundström et al. 2007a). Furthermore, an increased soil moisture context can cause an increased $f_{n}$ of $10 \%$ (Mayer 1985). Consider that the trees were tested under different weather conditions and during two successive years, this effect cannot be neglected. Unfortunately, the effect could not be quantified because no measurements of the soil moisture were carried out.

During this study, the main findings were (1) that the wind-tree interaction can be modelled using viscous damping for all modes of vibration and (2) that the natural frequencies of a tree growing on subalpine forested slope do not differ between fall-line and cross-slope direction. Both these findings have contributed to a deeper understanding on how to model the tree response when exposed to wind forces.

Acknowledgments This study was supported by the Board of the Swiss Federal Institutes of Technology. We thank the landowners of the experimental sites for allowing us to perform the experiments, "Forstwerkhof Davos" for providing useful help during the fieldwork, Holger Simon for conducting the field experiments, 
Prof. Dr. Alessandro Dazio (Institute of Structural Engineering, ETH, Zurich, Switzerland) and the two anonymous reviewers that provided useful comments on an earlier version of this paper.

\section{References}

Agneni A, Balis-Crema L (1989) Damping measurements from truncated signals via Hilbert transform. Mech Syst Signal Proc $3: 1-13$

Bachmann H, Ammann W (1987) Vibrations in structures induced by man and machines. Structural Engineering Document 3e, Int. Assoc. for Bridge and Struct. Engng. IABSE-AIPC-IVBH, Zürich, Switzerland

Baker CJ (1997) Measurements of the natural frequencies of trees. J Exp Bot 48(310):1125-1132

Bartelt P, Stöckli V (2001) The influence of tree and branch fracture, overturning and debris entrainment on snow avalanche flow. Ann Glaciol 32:209-216

Clough RW, Penzien J (1993) Dynamics of structures. McGraw-Hill, New York

Di Iorio A, Lasserre B, Scippa GS, Chiatante D (2005) Root system architecture of Quercus pubescens trees growing on different sloping sonditions. Ann Bot 95:351-361

Dorren LKA, Berger F (2006) Stem breakage of trees and energy dissipation during rockfall impacts. Tree Physiol 26:63-71

Ellenberg H (1996) Vegetation Mitteleuropas mit den Alpen in ökologischer, dynamischer und historischer Sicht. Ulmer, Stuttgart

Gardiner BA (1989) Mechanical characteristics of Sitka spruce. Occasional Paper 24, Forestry Commission, Edinburgh

Gardiner BA (1992) Mathematical modelling of the static and dynamic characteristics of plantation trees. In: Franke J, Roeder A (eds) Mathematical modelling of forest ecosystems. Sauerländer, Frankfurt/Main, pp 41-60

Hoag DL, Fridley RB, Hutchins JR (1971) Experimental measurement of internal and external damping properties of tree limbs. Trans ASAE 14:20-28

Holbo HR, Corbett TC, Horton PJ (1980) Aeromechanical behaviour of selected Douglas-fir. Agr Meteorol 21:81-91
Johnson R (1999) Progression of the dynamic properties of large suspension bridges during construction - a case study of the Höga Kusten bridge. Ph.D. thesis Department of Structural Engineering, Royal Institute of Technology, Stockholm, Sweden

Jonsson MJ, Foetzki A, Kalberer M, Lundström T, Ammann W, Stöckli V (2006) Root-soil rotation stiffness of Norway spruce (Picea abies (L.) Karst) growing on subalpine forested slopes. Plant Soil 285:267-277

Lundström T, Heiz U, Stoffel M, Stöckli V (2007a) Fresh wood in bending: linking the mechanical and growth properties of a Norway spruce stem. Tree Physiol (Accepted)

Lundström T, Simon H, Stoffel M, Jonsson MJ (2007b) Assessing the reactions and energy absorption of trees exposed to rockfall: a new method. Plant Soil (Submitted)

Mayer H (1985) Baumschwingungen und Sturmgefärdung des Waldes. Wissenschaftliche Mitteilung Nr. 51 Universität München - Meteorologisches Institut, Deutschland

Mayer H (1989) Windthrow. Philos Trans R Soc Lond Ser B Biol Sci 324:267-281

Meteoschweiz (2004) Messstation Davos http://www.meteoschweiz.ch/de/Klima/Klimapublikationen/IndexKlimapublikationen.shtml

Milne R (1991) Dynamics of swaying of Picea sitchensis. Tree Physiol 9:383-399

Moore JR, Maguire DA (2004) Natural sway frequencies and damping ratios of trees: concepts, review and synthesis of previous studies. Trees Struct Funct 18:195-203

Peltola H (1996) Swaying of trees in response to wind and thinning in a stand of Scots pine. Bound Layer Meteor 77:285-304

Roodbaraky HJ, Baker CJ, Dawson AR, Wright CJ (1994) Experimental observations of the aerodynamic characteristics of urban trees. J Wind Eng Ind Aerodyn 52:171-184

White RG, White MF, Mayhead GJ (1976) Measurement of the motion of trees in two dimensions. Research Report 86, University of Southampton, Institute of Sound and Vibration, Southampton

Wood C (1996) Understanding wind forces on trees. In: Coutts MP, Grace J (eds) Wind and trees. Cambridge University Press, Cambridge, pp 133-164 